Landslides (2020) 17:1997-1999 DOI 10.1007/s10346-020-01456-w Published online: 17 June 2020 (c) Springer-Verlag GmbH Germany part of Springer Nature 2020

\author{
Leonardo Cascini - Michele Calvello - Sabatino Cuomo - Dario Peduto - Mariagiovanna \\ Moscariello - Gianfranco Nicodemo - Gaetano Pecoraro
}

\section{LARAM School 2020 goes online: the 15th doctoral school on "LAndslide Risk Assessment and Mitigation"}

\section{LARAM}

The International School on "LAndslide Risk Assessment and Mitigation” (LARAM) (http://www.laram.unisa.it) was founded at the University of Salerno in 2005. Since 2006, the most important initiative organized by LARAM has been the yearly 2-week school for PhD students and young doctors. The courses include lessons, tutorials and field training. Fourteen editions of the school have been organized so far: three held in Ravello, Italy (2006-2008); two in Salerno, Italy (2009-2010); three in Chengdu, China (2011-2012, 2015), in cooperation with the State Key Laboratory of Geohazard Prevention and Geoenvironment Protection SKLGP; five at the University of Salerno, Italy (20132014, 2016-2018); and one at the University of Lausanne, Switzerland (2019) (Cascini et al. 2019). For each edition of the school, $40 \mathrm{PhD}$ students were selected to attend the residential courses, among applicants working in civil engineering, environmental engineering, engineering geology, geology, geography or related fields. Figure 1 reports the distribution of the 210 universities providing the LARAM School with $591 \mathrm{PhD}$ students from 2006 to 2019. Since 2012, the school has also been attended, on a first come first served basis, by a few young doctors who defended their $\mathrm{PhD}$ thesis in the previous 5 years. Figure 2 shows group pictures from all the 14 editions of the school held so far.

Other initiatives organized by LARAM in the past 15 years include the following: a series (2006-2014) of 1-day workshops aiming at disseminating the latest developments in landslide risk management methodologies among researchers, professionals and authorities in charge of territory governance in Italy and Europe; two 1-week courses, held in Salerno, Italy (2011), and in Roorkee, India (2020), the latter in cooperation with IIT-Roorkee, the Norwegian University of Science and Technology and the Indian Geotechnical Society; two joint initiatives with the European alliance ALERT Geomaterials, including a session titled "Geomechanics in slopes" of an ALERT Workshop (2012) and the 8th Olek Zienkiewicz ALERT Course (2016); an academic trip for the LARAM staff organized with SKLGP (2015), including visits, presentations and discussions, in the five leading Chinese institutions; and two editions of "meet the experts" (2017, 2018), a series of short interviews with experts in the field of landslide analysis and management.

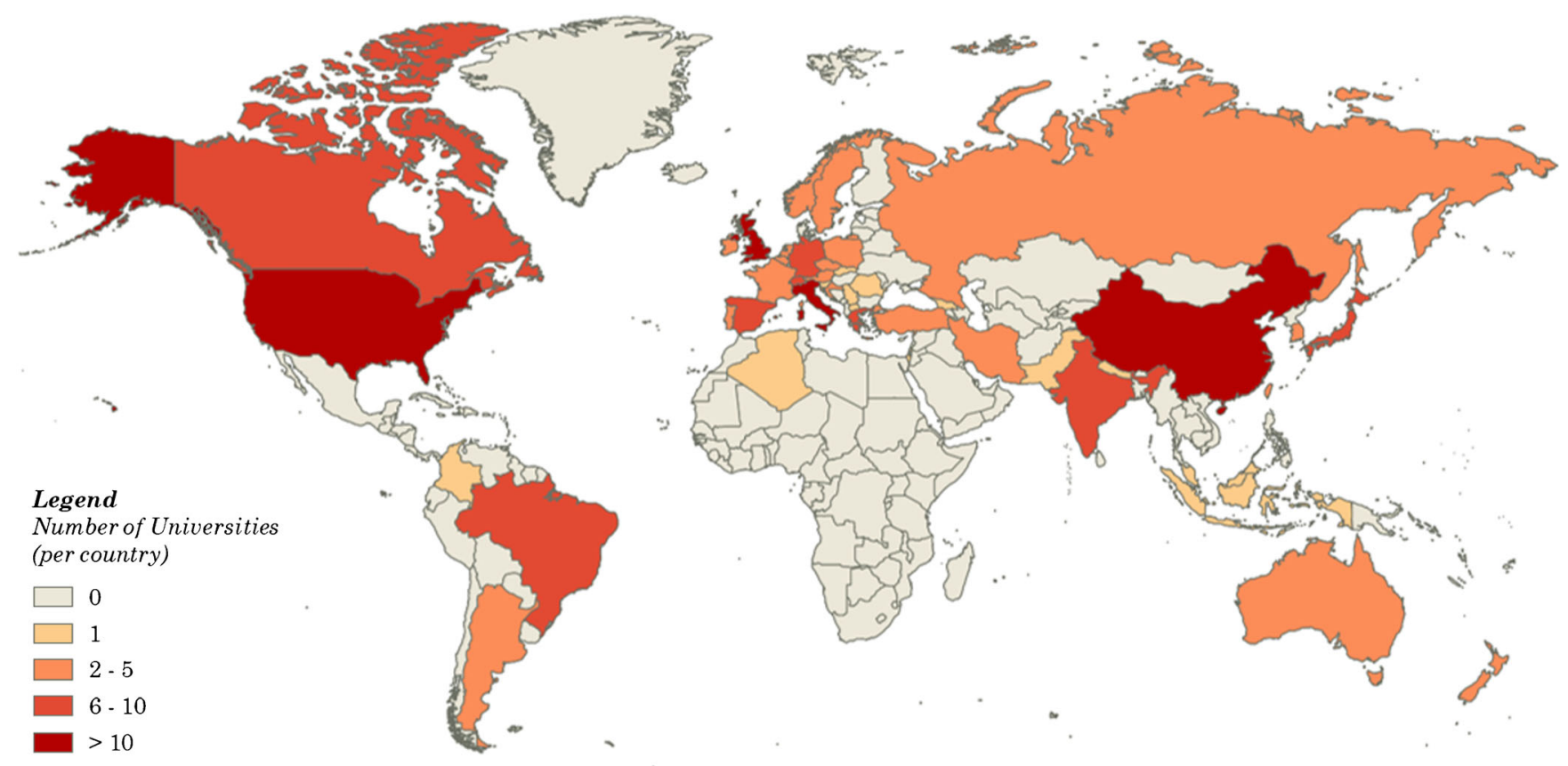

Fig. 1 Number of universities per country providing the LARAM doctoral school with PhD students from 2006 to 2019 


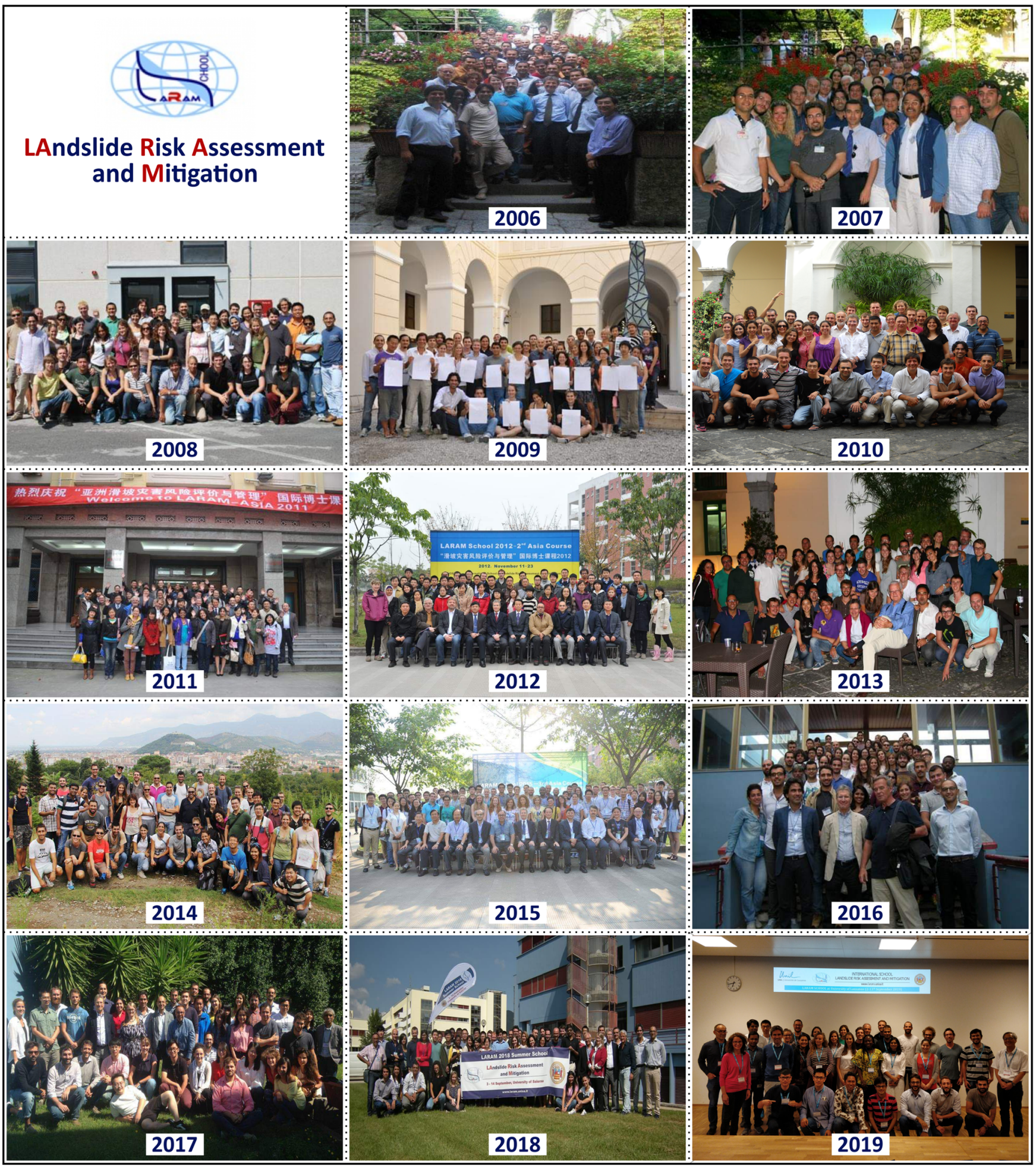

Fig. 2 Group pictures from the 14 editions of the LARAM School, from 2006 to 2019

LARAM School 2020

Since the first outbreak of the coronavirus disease 2019 (COVID-19) in the beginning of this year, all activities have largely been impacted worldwide by the pandemic, and its long-term impact remains uncertain. In academia, for instance, almost all universities in the world are currently running their educational activities online, and most of the international conferences and workshops planned for this year have been either cancelled or postponed to next year. The LARAM Scientific Committee (http://www.laram.unisa.it/laram/ sc_committee), following the evolution of the sanitary emergency and after some consultation with the coordination team, 
finally decided not to lose the occasion to teach and be together with the students also this year, despite the pandemic. To achieve this aim, the two middle weeks of September were confirmed as the dates of LARAM School 2020, yet it was decided to run a fully online edition of the school using a suitable online platform.

The following signature characteristics of LARAM remain unchanged, also in this year's online format of the school: two-week duration, international application call, selection among the applicants to form the class, final certificate of attendance to the students and mandatory and interactive participation of the students to the school activities. We are thus pleased to communicate that the 15th edition of the LARAM School will be held online, from Monday 7 to Friday 18 September 2020. The LARAM class will be composed of 40 selected $\mathrm{PhD}$ students and up to 10 young doctors. The deadline for applications is June 29, 2020.

The $40 \mathrm{PhD}$ students will be selected among applicants working in civil engineering, environmental engineering, engineering geology or related fields. The application form is available online at h t t p: / / www.laram.unis a.it/s chool/20200 nline/ application_phd_students. Candidates must include in their application a curriculum vitae and up to three recommendation letters. The selection will be based on an evaluation of the candidate's curriculum-including academic performance, previous research experience and publications - and on the content of the recommendation letter(s) in relation to the $\mathrm{PhD}$ course years, field of expertise and research topic. The registration fee for the selected students is Euro 250.

The young doctors ( $\max 10$ ), with $\mathrm{PhD}$ defended as far back as 5 years ago, will be able to register on a first come first served basis. Interested young doctors should fill the registration form available online at http://www.laram.unisa.it/school/ 20200 line/registration_young_doctors. The registration fee is Euro 400.

The programme of the school will consist of 5-h daily lectures and tutorials from Monday to Friday and a virtual field trip on Saturday 12 September. Following the tradition, the list of lecturers will be strongly international, and the contents and the sequence of the lessons will be structured to follow, as much as possible, the landslide risk management framework presented by Fell et al. $(2005,2008)$, paying a great attention to address both the most advanced theoretical issues as well as to present and discuss relevant landslide case studies coming from many different countries, within the following sessions:

- $\mathrm{S} 1$, Introduction to landslides

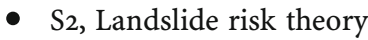

- $\mathrm{S}_{3}$, Landslide modelling

- S4, Landslide risk analysis and zoning

- S5, Landslide monitoring and mitigation

- S6, Landslide risk management and risk governance

During the school, the second LARAM Honour Lecture will be delivered. The LARAM Honour Lecture was established in 2018; it is awarded every 2 years and the awardee is invited to deliver it at that year's edition of the LARAM School. As per rules of the award, the LARAM Honour Lecture is delivered by "a distinguished researcher for outstanding contributions in scientific research and educational activities dealing with landslide risk assessment and mitigation". We are proud to communicate that the second LARAM Honour lecture will deal with "Reducing landslide risk - Emerging challenges, new paradigms and novel technologies" and will be delivered by Dr. Suzanne Lacasse from NGI, Norway.

Further details and the programme of the LARAM School 2020 are available on the LARAM web site at http://www.laram.unisa.it/ school/2020online/2020online.

\section{References}

Cascini L, Calvello M, Cuomo S, Jaboyedoff M, Peduto D (2019) LARAM School 2019: the yearly doctoral school on "LAndslide Risk Assessment and Mitigation". Landslides 16:1419-1421

Fell R, Ho KKS, Lacasse S, Leroi E (2005). A framework for landslide risk assessment and management. In: Landslide Risk Management, 3-25. Taylor \& Francis, ISBN-13: 9780415380430

Fell R, Corominas J, Bonnard C, Cascini L, Leroi E, Savage WZ (2008) Guidelines for landslide susceptibility, hazard and risk zoning for land use planning. Eng Geol 102(3):85-98

L. Cascini - M. Calvello (- $) \cdot$ S. Cuomo - D. Peduto - M. Moscariello

G. Nicodemo - G. Pecoraro

LARAM School,

University of Salerno,

Fisciano, Italy

Email: michele.calvello@gmail.com 